\title{
The Development and Utilization of Chinese Curriculum Resources Under the Sense of Community: Co-construction, Sharing and Using-together
}

\author{
Lei Yang and Lijun Yang *
}

\author{
Beijing Normal University, China \\ ${ }^{*}$ Corresponding author. Email: bnuyanglj@163.com
}

\begin{abstract}
The view of Chinese curriculum resources has gone through three stages: germination, development and clarification, and its connotation and extension have been gradually clarified and enriched in this process. Since the new century, with the deepening of the Chinese curriculum reform, the influence of Chinese curriculum resources on teachers' teaching has also deepened. Facing the diversified curriculum resources, how to effectively develop and utilize them has become a necessary research topic. Building a community based on curriculum resources, co-constructing, sharing, and using-together Chinese curriculum resources, becoming an effective mechanism for its development and utilization.
\end{abstract}

Keywords: Chinese curriculum resources, Building a community, Development and utilization.

\section{INTRODUCTION}

In order to meet the diversified and selective needs of Chinese courses, the awareness of course resources must be enhanced. [1] In different historical stages, there are significant differences in the understanding of the concept of curriculum resources. Therefore, this article attempts to clarify the historical development of curriculum resources and construct its theoretical basis. And under this premise, combined with the unique requirements of current educational reality for the development and utilization of curriculum resources, explore the path of curriculum resource development and utilization based on the sense of community.

\section{THE DEVELOPMENT AND} EVOLUTION OF THE CONNOTATION OF CHINESE CURRICULUM RESOURCES VIEW

The construction of curriculum resources should focus on the basic orientation of curriculum objectives and curriculum content. In a certain historical period, in order to meet the needs of curriculum goals, the teaching content and the content of the teaching materials are treated equally. This section attempts to analyse the content of 33 important curriculum documents from 1950 to 2021, and explore the development and evolution of curriculum resource concepts from a historical perspective.

\subsection{Embryonic Stage: The View of Curriculum Resources Based on the Content of Teaching Materials}

The basic education stage has long regarded the content of textbooks as equivalent to teaching content, and its ideological origin can be traced back to the "Interim Standards for Primary School Chinese Curriculum (Draft)" promulgated in 1950. "Key Points of Teaching Material Compilation" is included in the "Key Points of Teaching" in it, which shows that the content of the textbook is the content of the teaching to a certain extent. The "Primary School Chinese Syllabus (Preliminary Draft)" promulgated in 1955 divided the teaching content of elementary school Chinese into five types: reading, Chinese, writing, literacy and handwriting, although this syllabus is only available in a few provinces and cities. Its implicit teaching material view is still evident. In the "Full-time Primary School Chinese Syllabus (Draft)" and "Full-time Middle School Chinese Syllabus (Draft)" promulgated in 1963, it directly pointed out that "texts are the main teaching materials for cultivating students' reading and writing 
skills, and are the main basis of teaching."[2][3] Which means the development of curriculum resources can be equivalent to the development of the content of teaching materials.

\subsection{Development Stage: A Resource View of Textbooks and Courses That Take Extra- curricular Resources into Consideration}

In the "Chinese Syllabus for Full-time Ten-year Schools (Trial Draft)" promulgated in 1978, for the first time, "handling the relationship between in-class and extra-curricular" is an important focus for improving Chinese teaching in primary and secondary schools. Its basic essence is still based on in-class teaching, that is, based on the content of textbooks, supplemented by appropriate extracurricular learning. In the "Principles and Methods of Textbook Arrangement" section, the texts are clearly divided into three categories: lecture and reading text, reading text, and independent reading text for self-study. With the gradual increase in grades, the proportions of the three in the textbooks have also changed correspondingly. Since then, a curriculum resource content system based on the content of textbooks and taking into account the content of extracurricular learning has been initially constructed. With the "extracurricular activities" section officially proposed in the "Nine-year Compulsory Education Fulltime Chinese Syllabus (Preliminary Draft)", it has further catalysed the change in the concept of teaching materials. Among them, it is proposed that "extracurricular activities are an organic part of Chinese teaching", that is, the content of Chinese teaching is no longer simply limited to the content of textbooks, but more attention should be paid to the unique effect of extracurricular activities on the cultivation of students' Chinese literacy. This concept has been extended to 1992 "Nine-year Compulsory Education Full-time Chinese Syllabus (Trial)". In summary, these clarified the main role played by teaching materials in teaching, and gradually clarified the unique value of extracurricular learning content in the curriculum resource system, but did not clearly point out the importance of curriculum resources. Specific connotation.

\subsection{Clear Stage: An Inclusive Curriculum Resource View That Includes the Content of Teaching Materials}

In the "Nine-year Compulsory Education Full-time Primary School Chinese Syllabus (Trial Revised Edition)" promulgated in 2000 , it was the first time to "make full use of the language education resources in real life". [4]"The Teaching Syllabus (Revised Test Edition)" proposes that "keep close contact with social life and pay attention to the development of language teaching resources in real life". [5] The "Nine-year
Compulsory Education Full-time Junior High School Syllabus (Revised Trial Edition)" directly pointed out that "Communicating the links inside and outside textbooks, inside and outside the classroom, inside and outside the school." [6] Since then, the concept of teaching materials as teaching materials has been initially rectified. In 2001, "the development and utilization of curriculum resources" was compiled into the "Compulsory Education Chinese Curriculum Standards (Experimental Draft)" independently for the first time in 2001, and the specific connotation and extension of "curriculum resources" were clearly defined: Chinese curriculum resources Including classroom teaching resources and extracurricular learning resources, such as textbooks, teaching wall charts, reference books...[7] Chinese textbooks are clearly classified as curriculum resources. The constituent elements of Chinese curriculum resources have been clarified, which has laid a scope foundation for the subsequent development and utilization of curriculum resources.

\section{CURRICULUM RESOURCE DEVELOPMENT SYSTEM BASED ON COMMUNITY CONSCIOUSNESS}

Under the premise of clarifying the connotation and extension of Chinese curriculum resources, the development of curriculum resources based on the construction of a community of curriculum resources can help improve development efficiency, enrich resource content, improve resource structure, and reduce the burden on teachers.

\subsection{Realistic Basis: Objective Requirements of Multi-dimensional Factors}

The proposal of the Chinese Curriculum Resource Development Community is mainly affected by two factors, such as the three-level curriculum management policy and the dilemma of curriculum resource development. First, in the new round of Chinese curriculum reform, we will continue to implement the three-level curriculum management system. Under the premise of further regulating the development and implementation of local and school curriculum, the school's autonomy in running schools will be improved, and the education of compulsory education will be balanced and quality. development of. The main bodies of the three-level curriculum management are the state, locality and school respectively. At the national level, using curriculum standards as a characterization, formulate an overall plan for curriculum development, determine the categories and class hours of the national curriculum, and provide macro guidance for the implementation of the curriculum; at the local level, the provincial education administrative department plans according to the state's overall curriculum 
implementation plans that meet the needs of different regions; at the school level, while implementing national and local curriculum, develop or select courses that suit the characteristics of the school.

\subsection{Construction Principle: The Joint Participation of Multiple Subjects}

From macro policy, the Chinese curriculum resource development community include teacher and researcher at the country, region, and school levels. The three levels must have a clear division of labour to achieve complementary advantages. Schools are important organizers of curriculum resource development.[8]The local education administrative department should provide high-quality ecological conditions for the development of curriculum resource. For the government, the content and direction of the development of local and school need to be macroscopically guided.

From the middle view, the richness of the extension of Chinese curriculum resources determines the diversity of its participants. When curriculum resources are derived to the level of social life, the organizers of relevant institutions become an important member of the development of curriculum resources. Therefore, in the curriculum resource development community, it is necessary to extensively absorb members of various institutions and organizations, and provide support and help for the construction of Chinese curriculum resources from their respective professional fields.

From a micro perspective, the curriculum resource development community should be composed of multiple small unit development groups. When constructing a resource construction community, it is necessary to take into account different levels of learning, introduce professionals from universities and research institutions, and assist the development of Chinese curriculum resources from multiple dimensions such as theoretical construction and teaching practice.

\subsection{Basic Process: Cyclically Advanced Development Mode}

The process of developing and utilizing curriculum resources is not a one-way process, but a cyclical process of teachers from recognizing actions to results and judgments. [9] Comprehensive consideration of the objective factors that affect the development of curriculum resources and the basic principles of the joint participation of multiple subjects, and build a language curriculum resource development model with cyclical and advanced characteristics.

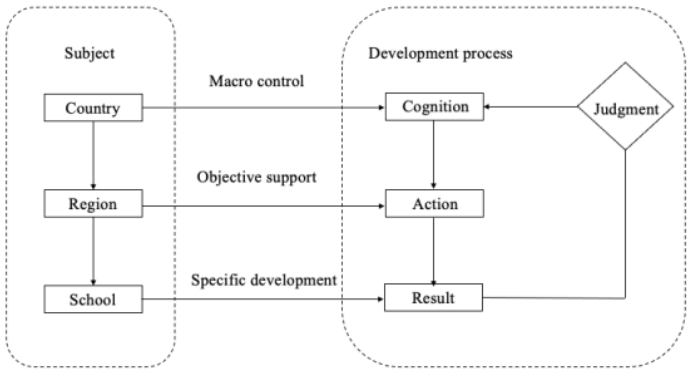

Chart 1 Chinese Course Resource Development Model

We should make full use of the resources provided by various organizations in the region to develop favourable conditions, and use small unit development groups as the basic organization to develop language curriculum resources. On the one hand, there are diversified channels for constructing Chinese curriculum resources, which can come from explicit ways such as daily life and regional cultural resources; it can also come from hidden ways such as important problems generated in the process of Chinese learning and academic achievements. On the other hand, the construction elements of Chinese curriculum resources will be affected by multi-dimensional objective factors and produce variations. Different teaching situations, regional characteristics, and user characteristics will give existing curriculum resources new connotations, and then produce diversified curriculum resources. In addition, affected by differences in educational beliefs, teachers will show significant differences in their own teaching styles when developing and using curriculum resources. Therefore, the development and utilization of Chinese curriculum resources with extensive participation of teachers provides a growing soil for its dynamic development.

\section{CURRICULUM RESOURCE UTILIZATION MECHANISM EMPHASIZING SHARING AWARENESS}

The "General High School Chinese Curriculum Standards (2017 Edition)" mentioned that " we should also pay attention to the complementarity and sharing of resources between schools." ${ }^{[1]}$ is a Chinese curriculum resource Sharing provides a policy basis. However, specific issues such as why and how to share and use need to be further clarified.

\subsection{Realistic Dilemma: The Contradiction of the Deficit between Resource Development and Utilization}

Since "Curriculum Resource Development and Utilization" appeared in the "Compulsory Education Chinese Curriculum Standards (Experimental Draft)" as an independent requirement in 2001, the field of basic education has set off the beginning of the development 
of curriculum resources. Even so, the lack of highquality curriculum resources is still a common problem in primary and secondary schools. ${ }^{[9]}$ The root of the contradiction between the extensive construction of curriculum resources and the lack of available resources lies in the weak sense of sharing. On the one hand, the state and local governments have insufficient publicity in constructing curriculum resource platforms, which leads to a waste of curriculum resources. On the other, there is no benign interaction mechanism between localities and schools, which has blocked the way of information sharing and weakened the sharing effect of curriculum resources. The weakness of teachers' selfsharing awareness is also an important subjective reason for the waste of curriculum resources. For one thing, after developing high-quality Chinese curriculum resources, teachers with pioneering spirits in various regions and schools have not shared the curriculum resources with teachers in other regions and schools due to factors such as their own awareness and lack of communication channels. For another, affected by their own abilities, teaching habits, and experience, it is difficult for teachers to make rational adjustments based on specific academic conditions when they are exposed to high-quality curriculum resources. At the same time, teachers will show an obvious resistance effect when they accept the concept of curriculum reform, and the important factor is that it increases the workload of teachers.

\subsection{Specific Measures: Boosting Modern Educational Technology}

The sharing of high-quality curriculum resources is an effective measure to improve the utilization of curriculum resources. The promulgation of this policy document puts the construction and excavation of curriculum resources in a strategic position to support the modernization of education. [10] Countries, localities, and schools should pay attention to the use of modern information technology, and provide material and policy guarantees for curriculum resource sharing through the development of reading resource libraries, cross-media reading platforms, and online course platforms.

Efforts will be made to build a community for the utilization of Chinese curriculum resources. The community provides a professional platform for teachers to jointly develop and utilize curriculum resources, enabling the group of teachers to process professional knowledge and experience into entities that can exist independently. [11] For the shared curriculum resource library, teachers in the community can use it directly after modifying it in accordance with specific academic conditions. After the curriculum resource library is built, it can be quickly promoted in the teacher community, which will help to increase the reuse rate of teaching resources, so as to achieve the purpose of reducing the workload of teachers and alleviating the impact of curriculum reform.

Help teachers establish a dynamic view of resources. The third-level curriculum resource development and reference, the development and circulation of curriculum resources between regions, and the development and sharing of curriculum resources between schools all endow the curriculum resources with the characteristics of fluidity. Only by recognizing the dynamic development of curriculum resources can teachers' subjective initiative be stimulated. It's also conducive to breaking the ideological fence of retreat and self-preservation, and opening up channels for the sharing of high-quality curriculum resources.

\section{REFERENCES}

[1] Ministry of Education of the People's Republic of China. Chinese Curriculum Standards for General High Schools (2017 Edition) [S]. Beijing: People's Education Press, 2018.

[2] Ministry of Education of the People's Republic of China. Chinese Syllabus for Full-time Primary Schools (Draft) [S]. Beijing: People's Education Press, 1963.

[3] Ministry of Education of the People's Republic of China. Chinese Syllabus for Full-time Middle Schools (Draft) [S]. Beijing: People's Education Press, 1963.

[4] National Education Commission of the People's Republic of China. Chinese Syllabus for Nine-year Compulsory Education and Full-time Primary School (Trial Revised Edition) [S]. Beijing: People's Education Press, 2000.

[5] Ministry of Education of the People's Republic of China. Chinese Syllabus for Full-time Regular Senior Middle Schools (Experimental Revised Edition) [S]. Beijing: People's Education Press, 2000.

[6] Ministry of Education of the People's Republic of China. Nine-year compulsory education full-time junior middle school Chinese syllabus (trial revision) [S]. Beijing: People's Education Press, 2000 .

[7] Ministry of Education of the People's Republic of China. Chinese Curriculum Standards for Full-time Compulsory Education (Experimental Draft) [S]. Beijing: Beijing Normal University Press, 2001.

[8] Zhu Qingguo. Case Study on the Development and Utilization of Chinese Curriculum Resources[J]. Chinese Construction, 2020(11): 38-41. 
[9] Bin Bin, Kong Fanzhe. Reflection on the status quo of teachers' utilization and development of curriculum resources and countermeasures for improvement $[\mathrm{J}]$. Educational Theory and Practice, 2015, 35(1): 56-60.

[10] Qiao Xuefeng, Li Wanhong. The development and utilization of curriculum resources in school-based teaching and research: the perspective of a community of practice[J]. Global Education Outlook, 2016(11): 32-42.

[11] Scardamalia,M.\& Bereiter,C.Knowledge Building and Knowledge Creation:Theory,Pedagogy and Technology[A].K. Sawyer.Cambridge Handbook of the Learning Sciences (2nd ed.) [C]. Cambridge: Cambridge University Press, 2014. 